\title{
Profil Pasien Trauma akibat Kecelakaan Lalu Lintas yang Dirawat di Instalasi Rawat Darurat Bedah RSUP Prof. Dr. R. D. Kandou Manado Periode 1 Januari - 31 Desember 2017
}

\author{
${ }^{1}$ Petrina C. Zai \\ ${ }^{2}$ Angelica Wagiu \\ ${ }^{2}$ Rangga Rawung
}

\author{
${ }^{1}$ Program Studi Pendidikan Dokter Fakultas Kedokteran Universitas Sam Ratulangi Manado \\ ${ }^{2}$ Bagian Ilmu Bedah Fakultas Kedokteran Universitas Sam Ratulangi - \\ RSUP Prof. Dr. R. D. Kandou Manado \\ Email: petrinazai@gmail.com
}

\begin{abstract}
Traffic related death and trauma are major health problems in developing countries. Traffic accident needs multidisciplinary approach. Data regarding the profile of traumatic patients due to traffic accidents are still limited especially in Indonesia. This study was aimed to obtain the profile of traumatic patients due to traffic accidents admitted to the emergency unit of Surgery Department, Prof. Dr. R. D. Kandou Hospital Manado, from 1st January to 31st December 2017. This was a descriptive retrospective study using medical record data of the patients. Samples were all traumatic patients due to traffic accidents admitted to the emergency unit of Surgical Department. The results showed that of 173 patients the majority were as follows: adults 121 patients (69.9\%), males 123 patients (71.1\%), drivers 113 patients $(65.3 \%)$, bikers 138 patients $(88.5 \%)$, without using safety equipment 93 patients $(59.6 \%)$, negative alcohol 141 patients $(81.5 \%)$, head trauma 91 patients (52.6\%), and outpatients as many as 130 patients $(75.1 \%)$.
\end{abstract}

Keywords: trauma, traffic accident

\begin{abstract}
Abstrak: Trauma dan kematian akibat kecelakaan lalu lintas (KLL) merupakan masalah kesehatan masyarakat yang utama di negara berkembang. Kecelakaan lalu lintas memerlukan penanganan dengan pendekatan multidisipliner. Data tentang profil pasien trauma akibat KLL terbilang masih sedikit khususnya di Indonesia. Penelitian ini bertujuan untuk mengetahui profil pasien trauma akibat KLL yang dirawat di Instalasi Rawat Darurat Bedah RSUP Prof. Dr. R. D. Kandou Manado periode 1 Januari s/d 31 Desember 2017. Jenis penelitian ialah deskriptif retrospektif menggunkan data rekam medik pasien. Sampel penelitian ialah semua pasien trauma akibat KLL yang dirawat di Instalasi Rawat Darurat Bedah RSUP Prof. Dr. R. D. Kandou Manado. Hasil penelitian menunjukkan bahwa dari 173 pasien KLL, didapatkan yang terbanyak ialah pasien usia dewasa 121 orang $(69,9 \%)$, jenis kelamin laki-laki 123 orang $(71,1 \%)$, pengendara 113 orang $(65,3 \%)$, pengguna motor 138 orang $(88,5 \%)$, tidak memakai alat pengaman 93 orang $(59,6 \%)$, negatif alkohol 141 orang $(81,5 \%)$, trauma kepala 91 orang $(52,6 \%)$, dan rawat jalan 130 orang $(75,1 \%)$.
\end{abstract}

Kata kunci: trauma, kecelakaan lalu lintas

Jumlah kendaraan bermotor di Indonesia meningkat tiap tahunnya, mengingat di era modern ini transportasi adalah kebutuhan pokok manusia. Tercatat di tahun 2016 kendaraan bermotor di Indonesia berjumlah lebih dari 128 juta, dimana satu tahun sebelumnya tercatat 120,7 juta, dan dua tahun sebelumnya yaitu tahun 2014 tercatat 
113,4 juta. ${ }^{1}$ Peningkatan populasi kendaraan bermotor mengakibatkan meningkatnya pula angka kejadian kecelakaan lalu lintas (KLL) di Indonesia. ${ }^{2}$

Angka trauma dan kematian akibat kecelakaan di dunia terbilang masih tinggi. Dikutip dari Global Status Report On Road Safety 2015, WHO, angka kematian akibat KLL didunia dari tahun 2007 - 2013 cukup konstan yaitu sekitar 1,25 juta jiwa disamping terjadi peningkatan jumlah kendaraan bermotor dan jumlah populasi manusia. ${ }^{3} \mathrm{Di}$ Indonesia sendiri berdasarkan data yang didapat dari catatan kecelakaan di Indonesia dalam buku "Polantas Dalam Angka Tahun 2013" sebanyak 100.106 kecelakaan dengan catatan 26.416 meninggal dunia, 28.438 korban luka berat, 110.448 korban luka ringan. ${ }^{4}$

Kecelakaan lalu lintas merupakan masalah kesehatan masyarakat yang perlu ditangani dengan pendekatan multidisipliner. ${ }^{5}$ Tanpa tindakan yang tepat, trauma akibat KLL diprediksi akan meningkat pada tahun 2020 menjadi peringkat ketiga beban penyakit global, dimana sebelumya pada tahun 1990 masih menduduki peringkat kesembilan. ${ }^{6}$

Masih minimnya data tentang profil pasien trauma akibat KLL serta pentingnya data ini untuk menjadi bahan informasi dan evaluasi dari berbagai pihak mendasari peneliti untuk melakukan penelitian terkait profil pasien trauma akibat kecelakaan lalu lintas khususnya yang dirawat di Instalasi Rawat Darurat Bedah RSUP. Prof. Dr. R. D. Kandou Malalayang mulai dari 1 Januari sampai dengan 31 Desember 2017.

\section{METODE PENELITIAN}

Jenis penelitian ini ialah deskriptif retrospektif dengan mengumpulkan data sekunder berupa data dari rekam medik pasien trauma akibat KLL yang dirawat di Instalasi Rawat Darurat Bedah RSUP. Prof. Dr. R. D. Kandou Manado periode 1 Januari sampai dengan 31 Desember 2017. Sampel penelitian ini ialah seluruh pasien trauma akibat KLL yang dirawat di Instalasi Rawat Daarurat Bedah RSUP Prof Dr. R. D. Kandou Manado periode 1
Januari sampai dengan 31 Desember 2017 yang memenuhi kriteria inklusi dan eksklusi.

\section{HASIL PENELITIAN}

Berdasarkan penelitian yang dilakukan di RSUP Prof Dr. R. D. Kandou Manado, didapatkan 173 pasien trauma akibat KLL yang memenuhi kriteria inklusi dan status pasien lengkap, dijabarkan seperti dibawah ini dalam Tabel 1-11.

Tabel 1. Distribusi jumlah pasien berdasarkan golongan usia

\begin{tabular}{lcc}
\hline Golongan usia & $\begin{array}{c}\text { Jumlah } \\
\text { pasien }\end{array}$ & Persentase \\
\hline$<18$ tahun & 40 & 23,2 \\
$18-59$ tahun & 121 & 69,9 \\
$\geq 60$ tahun & 12 & 6,9 \\
Total & 173 & 100 \\
\hline
\end{tabular}

Tabel 2. Distribusi jumlah pasien berdasarkan jenis kelamin

\begin{tabular}{ccc}
\hline Jenis kelamin & $\begin{array}{c}\text { Jumlah } \\
\text { Pasien }\end{array}$ & Persentase \\
\hline Laki - laki & 123 & 71,1 \\
Perempuan & 50 & 28,9 \\
\hline Total & 173 & 100 \\
\hline
\end{tabular}

Tabel 3. Distribusi jumlah pasien berdasarkan peran pasien sebagai pengguna jalan

\begin{tabular}{lcc}
\hline Peran pasien & $\begin{array}{c}\text { Jumlah } \\
\text { pasien }\end{array}$ & Persentase \\
\hline Pengendara & 113 & 65,3 \\
Penumpang & 43 & 24,9 \\
Pejalan Kaki & 17 & 9,8 \\
Total & 173 & 100 \\
\hline
\end{tabular}

Tabel 4. Distribusi jumlah pasien berdasarkan jenis kendaraan yang dinaiki

\begin{tabular}{ccc}
\hline $\begin{array}{c}\text { Jenis } \\
\text { kendaraan }\end{array}$ & Jumlah & Persentase \\
\hline Motor & 138 & 88,5 \\
Mobil & 18 & 11,5 \\
Total & 156 & 100 \\
\hline
\end{tabular}


Tabel 5. Distribusi peran pasien berdasarkan jenis kendaraan yang dinaiki

\begin{tabular}{ccccc}
\hline \multirow{2}{*}{$\begin{array}{c}\text { Peran } \\
\text { pasien }\end{array}$} & \multicolumn{2}{c}{$\begin{array}{c}\text { Jenis } \\
\text { kendaraan }\end{array}$} & \multicolumn{2}{c}{ Persentase } \\
\cline { 2 - 5 } & Motor & Mobil & Motor & Mobil \\
\hline Pengendara & 108 & 5 & 78,3 & 27,8 \\
Penumpang & 30 & 13 & 21,7 & 72,2 \\
Total & 138 & 18 & 100 & 100 \\
\hline
\end{tabular}

Tabel 6. Distribusi jumlah pasien berdasarkan pemakaian alat pengaman

\begin{tabular}{lcc}
\hline \multicolumn{1}{c}{$\begin{array}{c}\text { Alat } \\
\text { Pengaman }\end{array}$} & $\begin{array}{c}\text { Jumlah } \\
\text { Pasien }\end{array}$ & Persentase \\
\hline Memakai & 63 & 40,4 \\
Tidak & 93 & 59,6 \\
memakai & & \\
Total & 156 & 100 \\
\hline
\end{tabular}

Tabel 7. Distribusi pemakaian alat pengaman berdasarkan jenis alat pengaman

\begin{tabular}{lcccc}
\hline \multirow{2}{*}{ Alat pengaman } & \multicolumn{2}{c}{ Jenis kendaraan } & \multicolumn{2}{c}{ Persentase } \\
\cline { 2 - 5 } & Helm & $\begin{array}{c}\text { Sabuk } \\
\text { pengaman }\end{array}$ & Helm & $\begin{array}{c}\text { Sabuk } \\
\text { pengaman }\end{array}$ \\
\hline Memakai & 61 & 2 & 44,2 & 11,1 \\
Tidak memakai & 77 & 16 & 55,8 & 88,9 \\
Total & 138 & 18 & 100 & 100 \\
\hline
\end{tabular}

Tabel 8. Distribusi pemakaian alat pengaman berdasarkan peran pasien

\begin{tabular}{lcccc}
\hline \multirow{2}{*}{ Alat pengaman } & \multicolumn{2}{c}{ Peran pasien } & \multicolumn{2}{c}{ Persentase } \\
\cline { 2 - 5 } & Pengendara & Penumpang & Pengendara & Penumpang \\
\hline Memakai & 51 & 12 & 45,1 & 27,9 \\
Tidak Memakai & 62 & 31 & 54,9 & 72,1 \\
\multicolumn{1}{c}{ Total } & 113 & 43 & 100 & 100 \\
\hline
\end{tabular}

Tabel 9. Distribusi jumlah pasien berdasarkan ada tidaknya riwayat konsumsi alkohol

\begin{tabular}{lcc}
\hline $\begin{array}{c}\text { Konsumsi } \\
\text { Alkohol }\end{array}$ & $\begin{array}{c}\text { Jumlah } \\
\text { Pasien }\end{array}$ & Persentase \\
\hline Ada & 32 & 18,5 \\
Tidak Ada & 141 & 81,5 \\
Total & 173 & 100 \\
\hline
\end{tabular}

Tabel 10. Distribusi jumlah pasien berdasarkan lokasi trauma

\begin{tabular}{lcc}
\hline Lokasi trauma & $\begin{array}{c}\text { Jumlah } \\
\text { Pasien }\end{array}$ & Persentase \\
\hline Kepala & 91 & 52,6 \\
Leher & 1 & 0,6 \\
Toraks & 25 & 14,3 \\
Abdomen & 1 & 0,6 \\
Ekstremitas Atas & 7 & 4,1 \\
Ekstremitas Bawah & 31 & 17,9 \\
Multiple : & & \\
$\quad$ a. Kepala \& toraks & 4 & 2,3 \\
b. Kepala \& & 1 & 0,6 \\
$\quad$ ekstremitas atas & & \\
c. Kepala \& & 5 & 2,9 \\
$\quad$ ekstremitas & &
\end{tabular}

bawah
d. Kepala, toraks,
1
0,6 \& ekstremitas bawah
e. Leher \& ekstremitas bawah
f. Toraks \& $\quad 1 \quad 0,6$ abdomen
g. Ekstremitas atas $4 \quad 2,3$ \& ekstremitas bawah

Total 173 100

Tabel 11. Distribusi jumlah pasien berdasarkan jenis rawat

\begin{tabular}{ccc}
\hline Jenis rawat & $\begin{array}{c}\text { Jumlah } \\
\text { Pasien }\end{array}$ & Persentase \\
\hline Rawat jalan & 130 & 75,1 \\
Rawat inap & 43 & 24,9 \\
Total & 173 & 100 \\
\hline
\end{tabular}

\section{BAHASAN}

Dari hasil penelitian yang dilakukan dengan mengambil data pasien trauma 
akibat KLL yang dirawat di Instalasi Rawat Darurat Bedah RSUP Prof Dr. R. D. Kandou Manado periode 1 Januari sampai 31 Desember 2017 didapatkan jumlah pasien sebanyak 211 pasien, namun hanya 173 yang menjadi sampel penelitian, yaitu yang merupakan pasien trauma akibat KLL dan memenuhi kriteria inklusi. Pasien yang tidak memenuhi kriteria inklusi sebanyak 38 pasien karena datanya kurang lengkap, tidak dicatat ada tidaknya penggunaan alat pengaman.

Berdasarkan distribusi jumlah pasien menurut golongan usia didapatkan jumlah terbanyak dari golongan usia dewasa (yaitu antara 18 sampai 59 tahun) dengan jumlah 121 pasien $(69,9 \%)$. Golongan usia selanjutnya yang terbanyak yaitu dari golongan usia anak ( $<18$ tahun) dengan jumlah 40 pasien $(23,2 \%)$. Golongan usia lansia ( $\geq 60$ tahun) merupakan golongan usia paling sedikit mengalami trauma akibat kecelakaan lalu lintas. Hasil penelitian ini sejalan dengan penelitian yang dilakukan oleh Riandini, dkk 2015 dimana pasien trauma akibat kecelakaan lalu lintas tertinggi pada rentang usia 19 60 tahun, terbanyak kedua pada rentang usia $\leq 18$ tahun, dan paling sedikit pada usia $>60 \operatorname{tahun}^{7}$ meskipun penggolongan usianya sedikit berbeda.

Berdasarkan distribusi pasien menurut jenis kelamin, didapatkan 123 pasien $(71,1 \%)$ laki-laki dan sisanya 50 pasien $(28,9 \%)$ perempuan. Menurut WHO (2002) dalam artikel Gender and Road Traffic Injuries, laki-laki lebih berisiko mengalami trauma dan kematian akibat kecelakaan lalu lintas dikaitkan dengan jumlah laki-laki yang aktif mengemudi signifikan lebih banyak dibandingkan perempuan serta pola perilaku dengan risiko tinggi saat mengemudi. ${ }^{8}$

Pada distribusi pasien berdasarkan peran pasien sebagai pengguna jalan, pengendara menduduki tingkat pertama yaitu sebanyak 113 pasien $(65,3 \%)$ diikuti oleh penumpang yaitu sebanyak 43 pasien $(24,9 \%)$ dan yang paling sedikit yaitu pejalan kaki dengan 17 pasien $(9,8 \%)$. Tingginya jumlah pengendara disbanding- kan pengguna jalan lainnya (penumpang \& pejalan kaki) bisa disebabkan oleh faktor risiko terjadinya KLL yaitu faktor pengendara seperti yang dilaporkan oleh Gopalakrishnan bahwa pengendara $(78,5 \%)$ ialah penyebab terbanyak KLL dikarenakan faktor-faktor seperti banyak pengendara yang mengendari dengan sembrono dan cepat, tidak mematuhi atau mengikuti peraturan lalu-lintas, pemeliharaan kendaraan yang buruk, mabuk saat mengemudi, atau lelah. ${ }^{5}$

Pada distribusi jumlah pasien berdasarkan jenis kendaraan yang dinaiki, motor menduduki peringkat pertama dengan 138 pasien $(88,5 \%)$ diikuti mobil dengan jumlah pasien sebanyak 18 orang $(11,5 \%)$. Data ini selaras dengan data KLL di Indonesia tahun 2013 yang tercatat dalam Buku Polantas Dalam Angka 2013 dimana kendaraan yang paling banyak terlibat KLL ialah motor dengan jumlah 119.560 dari 168.183 jumlah total semua kendaraan. ${ }^{4}$ Hal ini bisa disebabkan karena jumlah kendaraan sepeda motor jauh lebih banyak dibandingkan mobil, seperti yang dilaporkan oleh Kementerian Perhubungan dalam Buku Statistik Perhubungan 2016, data terakhir tahun 2016 jumlah sepeda motor di Indonesia tercatat ada 106 ribu unit. ${ }^{1}$ Angka ini jauh lebih besar bila dibandingkan dengan jumlah mobil yang hanya 21 ribu unit. $^{1}$

Dari hasil penelitian jumlah pasien berdasarkan kendaraan yang dinaiki dapat dilihat bahwa dari 138 pengguna motor, 108 orang $(78,3 \%)$ merupakan pengendara, 30 orang $(21,7 \%)$ lainnya ialah penumpang sedangkan dari 18 pasien pengguna mobil, pengendara berjumlah 5 orang $(27,8 \%)$ dan 13 orang $(72,2 \%)$ lainnya merupakan penumpang.

Berdasarkan distribusi jumlah pasien menurut pemakaian alat pengaman, lebih banyak pasien yang tidak menggunakan alat pengaman dengan jumlah 93 orang $(59,6 \%)$, sedangkan yang memakai alat pengaman berjumlah 63 orang $(40,4 \%)$. Dari data jumlah pasien menurut pemakaian alat pengaman ini, juga dapat dilihat bahwa dari 138 pengguna motor lebih 
banyak yang tidak menggunakan alat pengaman dengan jumlah 77 orang $(55,8 \%)$ dan yang memakai alat pengaman sebanyak 61 orang $(44,2 \%)$. Perbedaan jumlah pengguna mobil yang memakai dan tidak memakai alat pengaman lebih signifikan dimana dari 18 orang pengguna mobil, hanya 2 orang $(11,8 \%)$ yang memakai alat pengaman, sisanya 16 orang $(88,2 \%)$ tidak memakai alat pengaman. Begitu pula dengan distribusi pemakaian alat pengaman menurut peran pasien sebagai pengguna jalan, faktanya lebih banyak yang tidak mengguanakan alat pengaman dengan jumlah 62 orang $(54,9 \%)$ dari total 113 pengendara dan 31 orang $(72,1 \%)$ dari jumlah keseluruhan 43 penumpang. Dari data ini bisa dilihat ternyata masih banyak pengguna kendaraan yang tidak taat berlalu lintas, dibuktikan dari cukup banyak jumlah orang yang tidak memakai alat pengaman. Padahal kewajiban menggunakan alat pengaman bagi pengguna kendaraan jelas tertulis dalam Undang-Undang no. 22 Tahun 2009 pasal 106. ${ }^{9}$ Dalam Buku Road Traffic Injury Prevention:Training Manual Unit 2 (Risk Factors For Road Traffic Injuries), WHO, dikatakan bahwa faktor risiko utama trauma bahkan kematian pada pengendara roda dua maupun roda empat ialah tidak memakai alat pengaman atau memakai namun cara pemakaian yang kurang tepat. ${ }^{10}$

Berdasarkan distribusi pasien menurut ada-tidaknya riwayat konsumsi alkohol, didapatkan pasien positif alkohol dengan jumlah 32 orang $(18,5 \%)$ sedangkan 141 orang $(81,5 \%)$ lainnya tidak positif atau negatif alkohol. Walaupun jumlahnya sedikit, namun dapat dilihat bahwa alkohol ternyata juga mengambil peran dalam trauma akibat KLL. Hal ini selaras dengan tulisan dalam buku Road Safety Training Manual Unit 2 (Risk Factors For Road Traffic Injuries) dimana alkohol merupakan salah satu faktor risiko penyebab trauma akibat KLL. $^{10}$

Berdasarkan data distribusi jumlah pasien menurut lokasi trauma didapatkan hasil sebagai berikut: kepala dengan jumlah terbanyak yaitu 91 pasien $(52,6 \%)$, diikuti ekstremitas bawah 31 pasien (17,9\%), toraks 25 pasien $(14,3 \%)$, lokasi multipel 17 orang pasien $(9,8 \%)$, ekstremitas atas 7 pasien $(4,1 \%)$, leher 1 pasien $(0,6 \%)$, abdomen 1 pasien $(0,6 \%)$. Data yang didapatkan yaitu kepala merupakan lokasi trauma terbanyak; hal ini sesuai dengan yang dituliskan oleh Soertidewi et al. ${ }^{11}$ dalam buku Konsensus Nasional Penanganan Trauma Kapitis dan Trauma Spinal. Namun berbeda dengan Zhou et al. ${ }^{12}$ yang menyatakan bahwa leher merupakan lokasi trauma terbanyak setelah kepala. Hal ini bisa disebabkan oleh karena data yang didapatkn penulis tidak cukup banyak dan kurang lengkap. Untuk peringkat ketiga lokasi trauma terbanyak dalam penelitian ini yaitu toraks. Hal ini sejalan dengan yang dilaporkan oleh Labora et al. ${ }^{13}$ bahwa trauma toraks menduduki peringkat ketiga terbanyak pada kasus trauma akibat KLL.

Menurut data distribusi jumlah pasien berdasarkan jenis rawat, didapatkan hasil 130 pasien $(75,1 \%)$ di rawat jalan dan 43 pasien $(24,9 \%)$ di rawat inap.

\section{SIMPULAN}

Berdasarkan hasil penelitian ini dapat disimpulkan bahwa mayoritas pasien trauma akibat kecelakaan lalu lintas yang dirawat di RSUP Prof. Dr. R. D. Kandou Manado berada pada golongan usia dewasa (18-59 tahun), jenis kelamin laki-laki, peran sebagai pengguna jalan atau pengendara, jenis kendaraan yang dinaiki ialah motor, tidak menggunakan alat pengaman saat kejadian, negatif alkohol atau tidak mengonsumsi alkohol, lokasi trauma pada kepala, dan jenis rawat jalan.

\section{SARAN}

Disarankan bagi peneliti selanjutnya agar menambah jumlahk sampel yang diteliti serta data lain seperti distribusi trauma kepala berdasarkan peran pasien sebagai pengguna jalan dan distribusi usia menurut peran pasien sebagai pengguna jalan.

Disarankan kepada Bagian Rekam Medik RSUP Prof. Dr. R. D. Kandou Manado agar kedepannya lebih memper- 
banyak pendataan rekam medik yang dibutuhkan untuk penelitian.

\section{DAFTAR PUSTAKA}

1. Kementerian Perhubungan. Statistik perhubungan 2016. Jakarta: Kementerian Perhubungan, 2017; p. 77.

2. Najid. Estimasi tingkat kecelakaan lalu lintas nasional dan 6 propinsi di pulau Jawa Indonesia. Simposium Nasional RAPI XI FT UMS, 2013.

3. World Health Organization. Global status report on road safety. Geneva: World Health Organization, 2015.

4. Markas Besar Kepolisian Negara Republik Indonesia Korps Lalu Lintas. Polantas dalam angka tahun 2013. Jakarta: Markas Besar Kepolisian Negara Republik Indonesia Korps Lalu Lintas, 2014.

5. Gopalakrishnan S. A public health perspective of road traffic accidents. J Family Med Prim Care. 2012;1(2):14450.

6. Ameratunga S, Hijar M, Norton R. Road traffic injuries: confronting disparities to address a global-health problem. Lancet. 2006;367:1533-40.

7. Riandini IL, Susanti R, Yanis A. Gambaran luka korban kecelakaan lalu lintas yang dilakukan pemeriksaan di RSUP Dr. M. Djamil Padang. J Kesehatan Andalas 2015;4(2).

8. World Health Organization. Gender and road traffic injuries. Geneva: World Health Organization; 2002.

9. Undang-Undang Republik Indonesia No. 22 Tahun 2009 tentang Lalu Lintas dan Angkatan Jalan.

10. World Health Organization. Road traffic injury prevention: training manual. Geneva: World Health Organization, 2004.

11. Soertidewi L, Misbach J, Sjahrir H, Hamid A, Jannis J, Bustami M, editors. Konsensus nasional penanganan trauma kapitis dan trauma spinal 2006. Jakarta: Perdossi, 2006.

12. Zhou SW, Guo LX, Zhang SQ, Tang CY. Study on cervical spine injuries in vehicle side impact. TOMEJ 2010; 4:29-35.

13. Labora JR, Kristanto EG, Siwu JF. Pola trauma toraks pada kecelakaan lalu lintas yang menyebabkan kematian di Bagian Forensik dan Medikolegal RSUP Prof. Dr. R. D. Kandou periode Januari 2013-Januari 2014. JBM. 2015;7(1):42-7. 